\title{
Bart Curvers: Arbeidsgeneeskunde is een mooie metier
}

Katrien Mortelmans, Dick van Putten

In TBV 2 van 2013 is de Visienota voor de toekomst van de arbeidsgeneeskunde in België beschreven. Tijd voor een interview met een van de verantwoordelijke auteurs, de voorzitter van de Belgische Beroepsvereniging voor Arbeidsgeneesheren, dokter Bart Curvers.

Waarom zou een bedrijfsarts of verzekeringsarts in Nederland moeten overwegen om in België te komen werken als arbeidsgeneesheer? Eerst en vooral om het Bourgondische leven, hè. Anderzijds is het salaris van een verzekeringsarts of bedrijfsarts in Nederland waarschijnlijk beter. Ten tweede omdat er veel vacatures voor arbeidsgeneesheren - wat jullie bedrijfsartsen noemen zijn. Elke Belgische werkgever met een of meer werknemers heeft immers verplicht preventieve ondersteuning nodig. Dat is bij wet vastgelegd.

In wat voor werkomgeving kan een arbeidsgeneesheer in België werken? Sommige Belgische arbeidsgeneesheren werken in een Interne Dienst voor Preventie en Bescherming op het Werk: een preventiedienst opgericht door en gelokaliseerd in een groot en goed georganiseerd bedrijf.

Het merendeel van de Belgische arbeidsgeneesheren werkt voor een van de Externe Diensten voor Preventie en Bescherming op het Werk. In België zijn er zo'n I 5. Je kunt zo'n externe dienst nog het best vergelijken met de Nederlandse arbodiensten van de jaren negentig.

Dergelijke interne of externe preventiediensten zijn multidisciplinair: er werken niet enkel arbeidsgeneesheren, maar ook bedrijfsverpleegkundigen, ergonomen, psychologen, arbeidshygiënisten, veiligheidsingenieurs, enzovoort, die als team kleine en grote werkgevers adviseren over welzijn, gezondheid en veiligheid op de werkplaats.

Is de jobinhoud van de Belgische arbeidsgeneesheer sterk verschillend van de Nederlandse bedrijfsarts?

Toch wel. De Belgische arbeidsgeneesheer houdt zich in essentie bezig met preventie. Nagaan of een werknemer terecht verzuimt of behandelingen voorschrijven zit niet in zijn opdracht. Het onderscheid tussen de werkdomeinen van verzekeringsarts/controlearts, dat van de behandelend

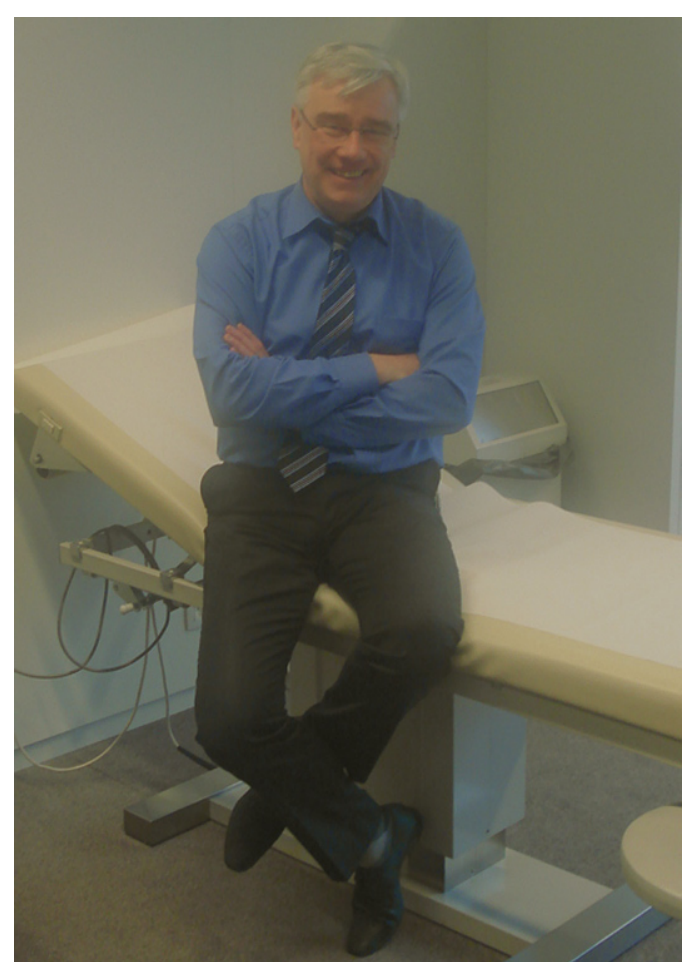

Bart Curvers

arts en ons domein van de arbeidsgezondheidszorg is strikter.

Hoe waakt de Belgische

arbeidsgeneesheer over zijn

onafhankelijkheid? Hij moet

werknemer én werkgever adviseren?

De onafhankelijkheid van de Belgische arbeidsgeneesheer ten opzichte van de (klant)werkgever wordt goed en positief aanvaard. Die onafhankelijkheid is ook wettelijk vastgelegd.

De wijze waarop de arbeidsgeneesheer daar persoonlijk mee omgaat, is essentieel; je moet vanaf het begin duidelijk maken waar die grenzen liggen. Want als je eenmaal je autonomie vrijgeeft, dan ben je ze kwijt, hè.

Bij interne diensten van grote werkgevers wordt die onafhankelijkheid strikt nageleefd. Bij externe diensten wordt een conflict met het klantbedrijf wel eens opgelost door wisseling van arbeidsgeneesheer. Dit gebeurt echter zelden.

Hoe zit het met de opleiding in België? De opleiding tot arbeidsgeneesheer is in België vrijwel gratis. Bovendien kan je de opleiding goed combineren met werken in deeltijdregime. 
U spreekt enkel over arbeidsgeneesheren in België. Worden de verzekeringsartsen ook vertegenwoordigd door u?

Ik word geïnterviewd als voorzitter van de BBvAG, de Belgische BeroepsVereniging voor Arbeidsgeneesheren (www.bbvag.be). Wij vertegenwoordigen circa $45 \%$ van de arbeidsgeneesheren. De verzekeringsartsen hebben een aparte vereniging. En de huisartsen ook.

Als er zoveel voordelen zijn aan het werken als arbeidsgeneesheer in België: waarom is er dan een tekort?

De Belgische arbeidsgeneesheer heeft een imagoprobleem bij het medische corps.

Vroeger hadden we nog heel wat huisartsen die als ze het harde werken in solopraktijken beu waren - een tweede loopbaan als arbeidsgeneesheer startten. Dat is nu voorbij. Recentelijk is de Belgische huisartsgeneeskunde geherwaardeerd, ook financieel.

Daarnaast is er ook een kleinere instroom van net afgestudeerde artsen. In België zijn er ingangsexamens en contingentering van het aantal artsen dat mag afstuderen. Dan komt de sociale geneeskunde in competitie met de huisartsgeneeskunde en de specialistische geneeskunde. En dan speelt ons slechtere imago ons parten.

\section{In België zijn er}

ingangsexamens en

contingentering van

\section{het aantal artsen dat \\ mag afstuderen. En dan \\ speelt ons slechtere}

imago ons parten.

\author{
Wat doet de BBvAG voor de \\ verbetering van het imago \\ van de arbeidsgeneesheer?
}

Wij hebben onder meer een promotievideo gemaakt. Klassiek voor België: 5 minuten Nederlandstalige film, 5 minuten Franstalige film. Eén film waar je een geneesheer ziet die tegen grensoverschrijdend gedrag optreedt in een lokaal bedrijf. Een tweede film waar de arbeidsgeneesheer een longfunctieonderzoek uitvoert in ver- band met onderzoek naar werkgebonden astma. Zoek eens op YouTube naar 'arbeidsgeneeskunde BBvAG'. 'De promotiefilms worden getoond op de startersdag voor jonge geneesheren, als ze een keuze moeten maken voor de specialistische vervolgopleiding.

Verder streven we naar een betere bekendmaking van onze jobinhoud bij collega-artsen. We zoeken contact met de huisartsenverenigingen. We laten studenten geneeskunde al in de eerste jaren van de opleiding in aanraking komen met de arbeidsgeneeskunde.

Wat is het standpunt van de beroepsvereniging over dat tekort aan arbeidsgeneesheren? Kan het opgelost worden? De beroepsvereniging meent dat de oplossing onder andere ligt in het herschrijven van de wetgeving.

We moeten een kader scheppen waarin arbeidsgezondheidszorg anders georganiseerd mag worden, onder meer met minder nadruk op jaarlijkse preventieve onderzoeken door de arbeidsgeneesheer.

U pleit voor minder jaarlijkse preventieve onderzoeken. Hoeveel medische

onderzoeken verricht een Belgische arbeidsgeneesheer gemiddeld per dag? Arbeidsgeneesheren in een interne dienst voeren zo'n zes tot acht medische onderzoeken per dag uit. In externe diensten loopt het aantal medische onderzoeken op tot dertig per dag, als het er niet meer zijn. We moeten oppassen met die grote aantallen, je moet ook nog kwalitatief met mensen bezig kunnen zijn, want anders ben je zoals een collega van mij zegt - met 'vleeskeuring' bezig.

Het ideale is zo'n tien medische onderzoeken per dag, met een variatie in de duurtijd van de medische onderzoeken. Sommige medische onderzoeken vragen immers meer tijd.

Welk soort medische onderzoeken voeren jullie uit?

De cijfers die ik net noemde, verwijzen naar het geheel van medische onderzoeken. Het merendeel zijn jaarlijkse preventieve onderzoeken van werkende en veelal gezonde werknemers. Maar arbeidsgeneesheren voeren ook aanwervingsonderzoeken uit. Er zijn medische onderzoeken in het kader van langdurig verzuim en werkhervatting. En niet te vergeten de spontane raadpleging: elke werknemer die gezondheidsklachten heeft die hij wijt aan de arbeidsomstandigheden, kan bij de arbeidsgeneesheer terecht. 
Hoeveel procent van die medische onderzoeken is volgens u zinvol?

In de categorie van arbeidsgeneesheren die niets liever doen dan jaarlijkse preventieve medische onderzoeken, wordt het merendeel van die onderzoeken als zinvol ervaren.

Maar arbeidsgeneesheren die kritischer ingesteld zijn, achten - en dan schat ik - slechts 40 à 50\% van de jaarlijks verplichte medische onderzoeken zinvol.

Wat doen Belgische arbeidsgeneesheren als ze geen medische onderzoeken uitvoeren?

De ervaring van de beroepsvereniging is, dat externe diensten trachten het pakket medische onderzoeken te beperken tot $60-70 \%$ van de tijd. Tot $30 \%$ van de werktijd wordt dan voor een andere invulling opengehouden: bezoeken aan de werkplaats, administratie, werkgroepen in het bedrijf bijwonen, zetelen in preventieve raden waarin werkgever en werknemersvertegenwoordigers preventieve strategieën uittekenen (het Comité voor Preventie en Bescherming op het Werk), wetenschappelijk werk...

Ik denk dat dat zeer verstandig is om de jobvalorisatie en jobvariatie te waarborgen.

De Belgische Beroepsvereniging voor Arbeidsgeneesheren meent dat

de wetgeving voor het uitvoeren van

arbeidsgeneeskunde herschreven mag

worden. Wat bedoelt u concreet?

Vanuit de BBvAG en veel andere betrokken organisaties ontstond een 'Visienota voor de toekomst van de arbeidsgeneeskunde in België', gepubliceerd in TBV 2 van 2013. We geven daarin suggesties om het tekort aan arbeidsgeneesheren aan te pakken. Wij wensen op een vernieuwende manier arbeidsgezondheidszorg in België aan te bieden, met meer zinvolle inhoud voor de arbeidsgeneesheer én voor de bedrijfsverpleegkundige. Met daarnaast aandacht voor het evidence-based gebeuren.

Kortom, wij ijveren voor een inhoudelijk andere invulling van het takenpakket van de Belgische arbeidsgeneesheer, ondersteund door herschreven wetgeving en binnen dezelfde financiële portefeuille als nu.

Spreekt de beroepsvereniging

zich ook uit over de financiering

van de arbeidsgezondheidszorg?

Nee, de financieringsmodaliteiten is iets tussen de federale overheid, werkgevers en syndicale organisaties. Momenteel betaalt de werkgever een forfaitair bedrag per werknemer die hij in dienst heeft. Het bedrag is hoger of lager in functie van de beroepsrisico's waaraan de werknemer op de werkvloer blootgesteld wordt. De vereniging houdt zich vooral met inhoudelijke aspecten bezig.

Als op beleidsniveau besloten wordt af te stappen van forfaitaire financiering, volgt er dan een commercialisering van de externe diensten?

De kans dat het zo'n vaart loopt is erg klein. Daar is België veel te behoudend voor en zijn onze sociale partners waaronder de syndicaten te sterk. De Belgische vakbonden ijveren sterk voor de bescherming van werknemers in precaire arbeidssituaties. Een commercialisering van de bedrijfsgezondheidszorg zou net die zwakkere groepen in de eerste plaats kwetsen. De syndicale organisaties en overheden kijken vandaag al nauwlettend naar de dienstverlening aangeboden door externe diensten. Daar is een neiging om te focussen op de commercieel interessante en dus veelal grotere bedrijven. En de kleine bedrijven, waar net veel veiligheids- en gezondheidsproblemen zijn, bijvoorbeeld de dienstenchequebedrijven met kuisvrouwen of kleine maar risicovolle bouwbedrijven, krijgen onvoldoende aandacht.

\section{De Belgische vakbonden ijveren sterk voor de bescherming van werknemers in precaire arbeidssituaties. Een} commercialisering van de bedrijfsgezondheidszorg
zou vooral die zwakkere groepen kwetsen.

\footnotetext{
Wat is de kans dat een wetswijziging met alternatieve invulling van de job van de arbeidsgeneeskunde werkelijk gerealiseerd wordt?
} De 'Visienota voor de toekomst van de arbeidsgeneeskunde in België' is neergelegd bij het ministerie van tewerkstelling. Een deel is al opgepikt in de beleidsnota van de minister van Arbeid van 
december 20I2. Ook onze adviezen om de arbeidsgeneesheer meer in te schakelen bij verzuim en werkhervatting kan je daarin lezen.

Heeft de Belgische arbeidsgeneesheer dan momenteel geen taak in verzuim? De Belgische sociale zekerheid vangt voornamelijk arbeidsongeschiktheden op, niet de werkgever. De huisarts of specialist maakt een arbeidsongeschiktheidsattest op als een werknemer door ziekte niet kan werken. De werkgever betaalt de eerste vier weken van het verzuim het loon door. De werkgever kan een controlearts (een private verzekeringsarts) sturen om de legitimiteit van het verzuim na te gaan. Niet alle werkgevers maken gebruik van dit controlesysteem.

Na 4 weken arbeidsongeschiktheid moet de werknemer zich aanmelden bij de ziekteverzekering. De mutualiteitsarts (een sociale verzekeringsarts) controleert dan het recht op een arbeidsongeschiktheidsuitkering. De zieke werknemer is dan niet meer financieel ten laste van de werkgever.

U wilt dat arbeidsgeneesheren meer betrokken zijn bij re-integratietrajecten. De BBvAG wil graag dat arbeidsgeneesheren zo vroeg mogelijk betrokken worden bij re-integratie na ziekte of ongeval. De verzekeringsartsen en curatieve artsen hebben immers geen goed zicht op de arbeidsomstandigheden en zelden een aanspreekpunt op de werkvloer. De arbeidsgeneesheer heeft dat wel.

De werkgever moet vandaag de dag al de arbeidsgeneesheer op de hoogte brengen van iemand die langdurig ziek is. Dat is een wettelijke verplichting. Bij grote bedrijven lukt dat: de arbeidsgeneesheer krijgt informatie en contacteert de afwezige werknemer om te praten over wat er aan hand is - arbeidsgerelateerde gezondheidsklachten, conflict op het werk, andere werkplek nodig, enzovoort - zonder enige verplichting voor werknemer of werkgever voor re-integratie of aanpassingen.

Bij kleinere bedrijven loopt het betrekken van de arbeidsgeneesheer bij verzuim en re-integratie moeilijker.

En hoe moet het overleg tussen

behandelend arts, verzekeringsarts,

arbeidsgeneesheer - allen betrokken

in het verzuim en re-integratieproces

verlopen?

Het streven is nu om op een e-healthplatform elektronische dossiers samen te laten komen in een aparte virtuele ruimte. De dossiers kunnen allemaal gelinkt worden aan het rijksregisternummer van de werknemers. Op deze manier kunnen behandelend arts, mutualiteitsarts en arbeidsgeneesheer onderling communiceren over de re-integratie van individuele werknemers. Maar dit is nog toekomstmuziek. Vooreerst is het elkaar kennen van primordiaal belang.

Heeft de beroepsvereniging ook een taak in navormingopleidingen?

Wij organiseren een tweedaags symposium, de nationale dagen voor arbeidsgeneeskunde. Daar komen 250-300 deelnemers naartoe waarvan de helft geen lid is van de vereniging.

Heeft de beroepsvereniging ook een rol bij het maken van richtlijnen? Daarover moet ik eerlijk zeggen: 'Onze noorderburen zijn daar beter in.'

Wat vinden de overheid, de werkgeversorganisaties en de werknemersorganisaties in België van de arbeidsgeneeskunde, heeft u daar een idee van?

De overheid vindt de arbeidsgeneeskunde belangrijk, daar ben ik van overtuigd.

De werkgeversorganisaties dringen aan op 'boter bij de vis'. Ik kan ze ook geen ongelijk geven, de arbeidsgeneeskunde wordt toch door hen gefinancierd.

De vakorganisaties schatten arbeidsgeneeskunde zeer hoog in. Die vinden het een verworvenheid dat er medisch toezicht is. De arbeidsgeneesheer is er voor hun leden, voor de werknemer in het algemeen.

Politiek wordt arbeidsgeneeskunde dus gedragen. Maar we moeten dringend bewijzen dat preventie werkt en we ons geld ook waard zijn.

Is er een probleem, met het

aantonen dat preventie werkt?

Wij moeten meer uit onze schulp komen mét wetenschappelijk onderzoek. Die tendens leeft. Grote externe diensten hebben nu ook een wetenschappelijk departement, een wetenschappelijk directeur (Dr. Curvers knipoogt naar de interviewer die directeur $R \& D$ bij een externe dienst is.) Interne en externe diensten verzamelen massa's gezondheidsgegevens. Dergelijke databanken zijn een bron voor research. De data-analyse mag ambitieuzer: wij moeten uit die massa aan gezondheidsdata toch meer kunnen besluiten dan dat iedereen dikker en groter wordt en dat de bloeddruk stijgt bij de Vlaamse werknemer. Ik 
denk dat we vooral rond musculoskeletale problematiek en psychosociale problematiek meer moeten kunnen zeggen. Ook is er sinds I996, bij mijn weten, niets meer verschenen rond medicatiegebruik en werk.

Kent u TBV?

Ik ken het tijdschrift, maar weet niet of het een grote bekendheid geniet in Vlaanderen.

Is TBV geschikt voor arbeidsgeneesheren en verzekeringsartsen in België?

Ik denk dat de combinatie van arbeidsgezondheidszorg en verzekeringsgeneeskunde in één tijdschrift sterk is en dat men daar in Vlaanderen ook meer plezier van zou kunnen hebben. Als je praat over re-integratiebeleid, dan zouden die twee doelgroepen elkaar toch wat meer moeten leren kennen. En dat kan via zo'n tijdschrift.

Zijn er nog punten die niet aan de orde

zijn gekomen, maar die u wel graag wil

meegeven aan de lezers van TBV?

Ja, dat arbeidsgeneeskunde een mooi metier is!
KORT CV

Dokter Bart Curvers, voorzitter van Belgische Beroepsvereniging voor Arbeidsgeneesheren.

25 jaar ervaring als arbeidsgeneesheer, onder meer bij:

de Externe Dienst Preventie en Bescherming op het Werk 'IDEWE';

de Interne Dienst Preventie en Bescherming op het Werk 'KBC bank en verzekering'.

Stichtend lid 'Vlaamse vereniging Brandweerartsen'.

Stichtend lid en momenteel nog penningmeester VVIB-AMTI (Vereniging voor interne bedrijfsartsen).

Lid RvB en voorzitter BBvAg-APBMT.

Lid Vlaamse erkenningscommissie diensten Medisch Toezicht.

Lid RvB Europese Club ter bevordering van de Gezondheid op het Werk.

NOOT

I. www.youtube.com/watch?v=ygWm-KZZiWo en www.you tube.com/watch?v=XiHTOXTqihM

\section{Macht en tegenmacht in de Nederlandse asbestregulering.}

Rob Ruers. Proefschrift Erasmus Universiteit Rotterdam, I5 maart 2012.

'Asbest doodt', 'Fijn venijn', het 'Beste Jaap briefje': ronkende teksten en sappige details illustreren dit rechtssociologisch proefschrift over de aanpak van de asbestproblematiek in Nederland. Hoe komt het dat het tot 1993 heeft geduurd voordat er een totaalverbod op het gebruik van asbest kwam, terwijl al in I969 duidelijk was dat asbest kankerverwekkend was? 'Bergvlas' is een oude benaming voor asbest en klinkt liefelijk, evenals het Franse 'amiante', maar asbest bleek fijn venijn te zijn (titel van een brochure van Leen van Vliet uit I982).

Bob Ruers heeft met dit proefschrift zijn jarenlange ervaring met dit onderwerp vlak voor zijn pensionering vastgelegd. De titel 'macht en tegenmacht' verwijst naar strijd: strijd om erkenning, strijd om financiële compensatie, strijd om asbest te verbieden en ook elementen van de klassenstrijd zijn in dit boek te vinden. Ruers heeft als advocaat meer dan Iooo 'asbestzaken' gedaan in de letselschadepraktijk. Daarnaast stond hij aan de wieg van het Comité Asbestslachtoffers, heeft een belangrijke rol gespeeld bij de totstandko- ming van het Instituut Asbestslachtoffers (IAS) en is hij politiek actief als senator voor de SP. Mooi zo'n 6o-plusser die promoveert, lid van een politieke partij, waarvan de opstelling in asbestzaken geduid is als 'een infame verkiezingsstunt van een splinterpartij die letterlijk over lijken gaat' (directeur Eternit, I989). Als je daar niet strijdbaar van wordt!

In dit boek wordt het maatschappelijke krachtenveld rond de asbestregulering in Nederland geanalyseerd en worden lessen uit de asbestgeschiedenis getrokken. Vanwege die lessen is dit boek ook voor bedrijfsartsen en verzekeringsgeneeskundigen interessant. Niet alleen vanwege de technische procedés die goed beschreven worden: asbestpapier (grondstof voor kunststof vloerbedekking) bevatte $85 \%$ asbest, in spuitasbest zat $60 \%$ asbest, $40 \%$ cement en een vleugje minerale olie. Hij laat duidelijk zien dat het duiden van patiënten met mesothelioom als 'asbestslachtoffers' in de media en in de rechtszaal de regulering in een stroomversnelling heeft gebracht; eenzelfde proces als ook bij OPS door 